\title{
Uma escultura de Ada Lovelace como recurso educativo para trabalhar gênero na computação
}

\author{
Nani Marques Castilho ${ }^{1}$, Clevi Elena Rapkiewicz ${ }^{2}$, Simone Vaccaro Fogazzi $^{2}$ \\ ${ }^{1}$ Faculdade de Educação -Universidade Federal do Rio Grande do Sul (UFRGS) \\ ${ }^{2}$ Colégio de Aplicação -Universidade Federal do Rio Grande do Sul (UFRGS)- \\ Porto Alegre - RS - Brasil \\ (nancast.nmc, clevirap@gmail.com; simone.fogazzi@ufrgs.br
}

\begin{abstract}
Several tools and strategies can be used to foster the debate about the low participation of women in the area of Computer Science. Disseminating reference models can be an option. This article reports the experience of inserting this debate in public schools, using as an educational resource a sculpture of Ada Lovelace made with electronic junk, promoting interdisciplinary activities. Testimonials of students who have had contact with the sculpture and participated in related workshops show that integrating art in this debate can have good results.
\end{abstract}

Resumo: Diversos instrumentos e estratégias podem ser usadas para fomenter o debate sobre a baixa participação de mulheres na área de computação. A falta de modelos de referência tem sido usada com frequência. Esse artigo relata a experiência de inserir o debate de gênero na computação em escolas públicas usando como recurso educativo uma escultura de Ada Lovelace feita com lixo eletrônico. Depoimentos de alunas e alunos que tiveram contato com a escultura denotam que integrar ate nesse debate pode trazer bons resultados.

\section{Introdução}

Não é novidade o fato que o número de mulheres nos cursos de computação é extremamente baixo. Nos mais de dois mil cursos superiores na área no Brasil, a quantidade de mulheres cai a cada ano (OLIVEIRA et al, 2014). Por outro lado, a quantidade de postos de trabalho na área vai mais do que dobrar até 2020, segundo notícia no portal da SBC tendo como fonte Code.org dos EUA (SBC, 2018). Essa é uma equação que não fecha, e um dos fatores para o não preenchimento dos postos de trabalho é o baixo número de mulheres na área, considerando-se, inclusive, que elas representam cerca de metade da mão-de-obra economicamente ativa.

Diversas estratégias têm sido usadas, no Brasil, para incentivar mais mulheres a entrar nesse mercado. Citem-se especialmente as diversas ações inseridas no programa Meninas Digitais da Sociedade Brasileira de Computação (SBC, 2019). Muitos projetos chancelados por esse programa tem foco na programação. Sem tirar a importância dessas ações, consideramos trabalhar com estratégias interdisciplinares podem quebrar a visão da 'dureza' dessa área das exatas. É nesse contexto que propomos uma estratégia de integrar Artes Visuais com Computação como forma de despertar o interesse pela área.

Entre os vários fatores que dificultam é a ausência de modelos de referência femininos a serem seguidos, de acordo com pesquisa da Microsoft (TROTMAN, 2017). Esse fator também é apontado por Schiebinger (2002). Porém, há que se discordar que 
haja ausência de modelos de referência. Há farta literatura mostrando que existem grandes personagens femininas na história da computação, como por exemplo Schartwz et al (2006) que destacam Ada Lovelace, Grace Hooper e as mulheres que trabalharam na programação do ENIAC. No caso específico de Ada Lovelace, encontramos farto material na Internet, e, no caso do Brasil, inclusive um livro infantil escrito por Silvia Amelia Bim (BIM, 2018).

A estratégia apresentada nesse artigo consiste no uso de uma escultura de Ada Lovelace desenvolvida com resíduos eletrônicos e oficinas com conhecimentos técnicos e de práticas Artes Visuais integradas em escolas públicas discutindo-se temas como gênero, obsolescência programada e descarte adequado de lixo eletrônico de forma interdisciplinar. Busca-se dar visibilidade a Ada Lovelace, um dos vários modelos de referência na computação, mas desconhecida de alunos e alunas da educação básica.

O artigo está organizado em 3 seções, além da presente introdução. Na seção 2, descrevemos do ponto de vista artístico a escultura desenvolvida. Na seção 3 apresentamos brevemente o tipo de trabalho que é feito em escolas públicas utilizando como recurso educativo esta escultura e breves depoimentos de alunos e alunas. Finalmente, na última seção apresentamos breves considerações finais.

\section{A escultura de Ada Lovelace, um corpo espartilhado}

A escultura criada pelo nosso projeto para apresentar Ada Lovelace (Figura 1) apoia-se em um painel de madeira, de onde sai um tronco de tela de arame bordado com teclas e componentes de teclados. Pendurada nele, uma grande saia armada e coberta por peças eletrônicas: disquetes, CDs, teclas e placas. O corpo não tem rosto: impressões de notas escritas por Ada, tabelas, diagramas, rascunhos, cartas e o memorial feito após sua morte, com um soneto escrito por ela - todos elementos relacionados à sua produção intelectual - preenchem o espaço acima do rígido corpete e através dele, ao fundo.

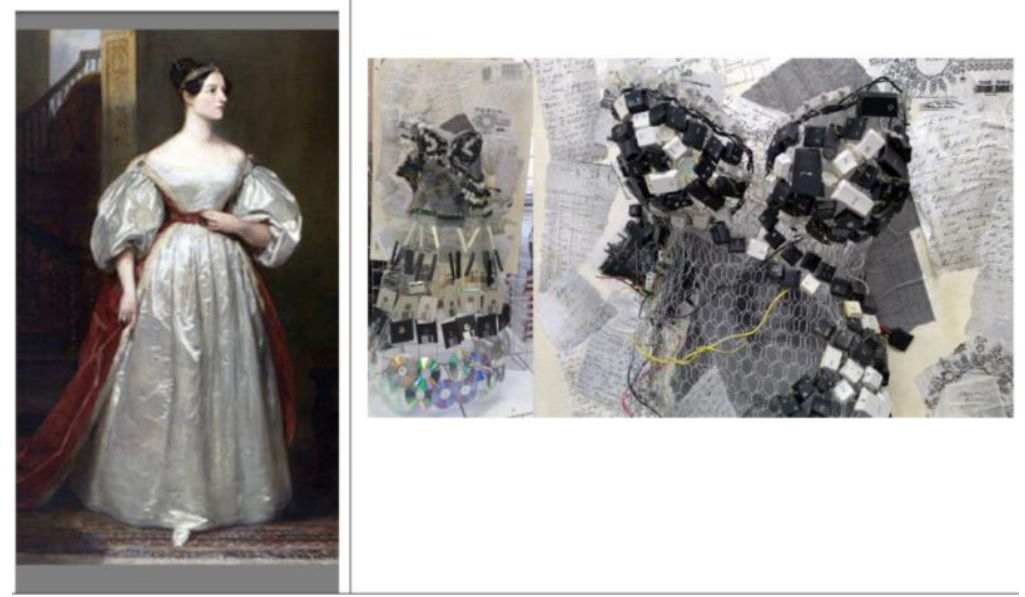

Figura 1. Retrato inspirador, Escultura inteira e detalhe do corpo

No período em que Ada viveu, compunha a moda feminina europeia uma peça de vestuário conhecida como espartilho. Ele apertava o corpo na região da cintura, tornando-a mais fina à força e levantando os seios. Escritos da época relatam que tal prática causava danos à saúde das mulheres. Restringindo a caixa torácica de forma a dificultar a respiração, seriam comuns desmaios, bem como problemas digestivos e posturais causados pelo uso de espartilhos apertados demais. Além disto a mobilidade do corpo espartilhado se prejudicava pela força com que a peça o comprimia, tornando difíceis movimentos como abaixar-se e dobrar, virar ou torcer o tronco. Importante denotar que seria injusto culpar as mulheres da época por se 
submeterem ao uso dos espartilhos. O Espelho Diamantino: Periodico de Politica, Litteratura, Bellas Artes, Theatro e Modas dedicado as Senhoras Brasileiras, em sua $3^{\mathrm{a}}$ edição, datada de 1827, traz em sua seção de Modas o seguinte trecho (p. 45-46):

\begin{abstract}
As Senhoras, obrigadas pela Ley da Natureza a agradar aos homens, e que quasi sempre o não conseguem senão pela sua formosura e ventagens exteriores, estão na restricta necessidade de estudar os meios de relevarem a sua Belleza, e de variarem os enfeitos que a accompanhão, em quanto aos homens que se appresentão na sociedade com as ventagens do valor, da sciencia, dos empregos, e da industria, nada diz tãobem como hum modo de vestir singelo.
\end{abstract}

É antiga a responsabilidade que se delega à mulher de atrair um homem, manter família, organizar casa e ainda estar sempre recatada e linda. Pode-se ver relações entre tais escritos e nosso contexto cultural: ainda se eximem homens de responsabilidades domésticas e de respeitarem mulheres dentro e fora de casa. Basta lembrar quantos creem que uma mulher arrumada na rua está à espera de sua "apreciação": a dita "Ley da Natureza" mencionada pelo homem redator d'O Espelho Diamantino em 1827.

A violência de gênero está também na crença, consciente ou não, de que as mulheres devem modificar seus corpos ou adorná-los para se tornarem aprazíveis, não necessariamente para si mesmas, enquanto aos homens cabem a intelectualidade e o prestígio por conquistas. A escolha de fazer o torso da escultura com uma tela de arame se baseia na relação feita entre a função do material, que é prender, delimitar, e o que ela representa: um corpo restrito por amarras sociais. Fernandes (2010) escreveu, sobre o local e o período em que viveu Ada: "Enquanto as mulheres da burguesia usavam a peça para reforçar e proteger sua distinção social, as trabalhadoras, em parte, a utilizavam para ofuscar ou fugir da sua origem, com a esperança de "entrar no mundo melhor'".

Pode parecer contraditório que um recurso supostamente usado para "dar valor" ao corpo feminino seja tão prejudicial a ele, diminuindo suas forças, capacidades e velocidades. No entanto, entendemos seu sucesso se levarmos em consideração que os espartilhos se disseminaram numa cultura em que o melhor que uma mulher poderia ser era frágil, precisando ser salva por algum homem forte e inteligente. Entendemos também, portanto, o quão significativo é o trabalho de Ada Lovelace.

De volta ao nosso objeto artístico, ressaltamos ainda que a falta de um rosto, de uma identidade, aliada à presença dos algoritmos e tabelas, aponta para outra questão importante sobre o lugar que nossa cultura dá às mulheres. Ainda que, em sua maioria, sejam postas em posições menores - em relação a homens de situação socioeconômica semelhante - tendo sua intelectualidade desqualificada, inúmeras mulheres se sobressaem e produzem grandes contribuições científicas.

\title{
3. Uma escultura visitando escolas
}

A simples exposição de uma obra de arte nem sempre desperta interesse de alunos e alunas. No entanto, quando acompanhando a exposição um conjunto de práticas pedagógicas na forma de oficinas, é possível despertar interesse dos participantes tanto para questão de gênero quanto das Artes Visuais. Acompanha a exposição da escultura de Ada Lovelace um conjunto de três oficinas (Tabela 1). 
Tabela 1. Oficinas associadas a escultura de Ada Lovelace

\begin{tabular}{|c|l|}
\hline Oficina & \multicolumn{1}{|c|}{ Foco } \\
\hline Desmontando & $\begin{array}{l}\text { Conhecer partes físicas de computador, desmontando-os, } \\
\text { reconhecendo a origem do material usado na escultura e, ao } \\
\text { mesmo tempo, entendo o funcionamento daquelas partes. }\end{array}$ \\
\hline $\begin{array}{c}\text { Montando e } \\
\text { conhecendo }\end{array}$ & $\begin{array}{l}\text { Montar algum artefato de artesanato ou artístico usando partes do } \\
\text { que foi desmontado. São apresentados exemplos de artefatos } \\
\text { pequenos (artesanato) e a escultura (objeto artístico). Desse } \\
\text { objeto, é contada a história e discute-se gênero e falta de } \\
\text { equidade entre gêneros com os alunos. }\end{array}$ \\
\hline $\begin{array}{l}\text { Por um consumo } \\
\text { mais consciente }\end{array}$ & $\begin{array}{l}\text { Discute-se o conceito de obsolescência programada, mostrando- } \\
\text { se que há indução do consumo de artefatos tecnológicos que nem } \\
\text { sempre são necessários e que tal consumo gera mais lixo } \\
\text { eletrônico. Este polui e gera problemas sobretudo em países } \\
\text { excluídos. Portanto, importante o consumo consciente e, havendo } \\
\text { lixo eletrônico, deve ser adequadamente descartado (divulga-se } \\
\text { os pontos de descarte na cidade do projeto). }\end{array}$ \\
\hline
\end{tabular}

Observe-se, pois, a ampla possibilidade de tratar temas diversos, de atuar de forma interdisciplinar, com destaque para Computação e Informática integrado com Artes Visuais. Porém, aspectos de Educação Ambiental podem ser trabalhados, temas de Química a partir dos vários metais presentes no lixo eletrônico, temas de Geografia de forma crítica (país produtores de tecnologia, consumidores e excluídos, conforme nos ensina Jeffrey Sachs). A duração de cada uma das oficinas depende do público-alvo, uma vez que atuamos no ensino regular a partir do $5^{\circ}$ ano, no Ensino Médio, ambos na modalidade regular e EJA (Educação de Jovens e Adultos). Como o foco deste artigo é a escultura em si não as oficinas, optamos por não detalhar o conteúdo das mesmas.

A seguir apresentamos brevemente algumas reações de alunos frente a obra apresentada.

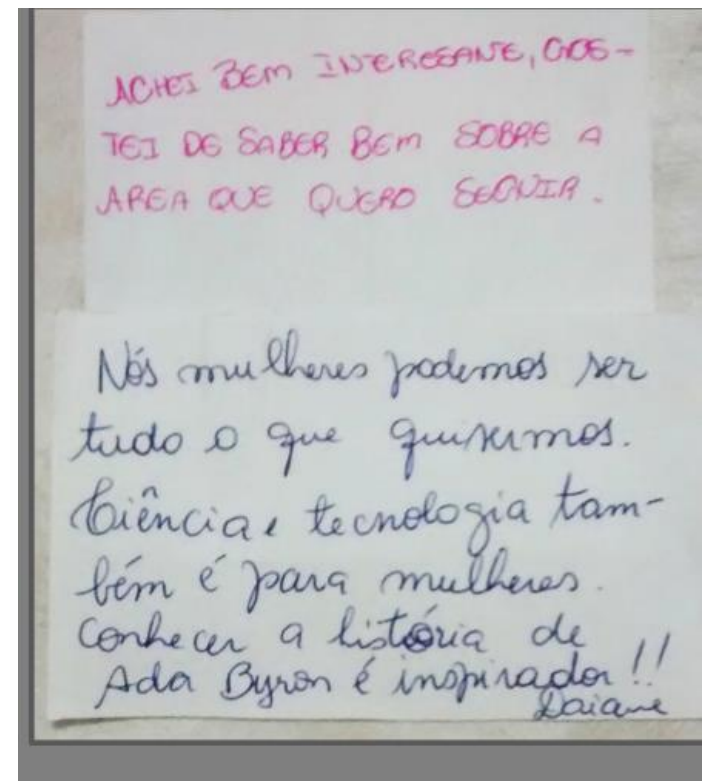

Figura 2 Depoimentos escritos espontâneos de alunos

Nas rodas de conversa sobre gênero a partir da apresentação da escultura de Ada Lovelace, deixamos disponíveis papeis para que os alunos e alunas, voluntariamente, manifestassem suas impressões. Dois exemplos são apresentados na Figura 2. 
Não foram poucas as vezes que observamos que o interesse da maioria das meninas era grande na história de Ada Lovelace e se reconheciam como pessoas com potencial para trabalhar onde quiserem. Antecedendo as conversas sobre Ada Lovelace, listamos no quadro profissões consideradas para homens e para mulheres. Nas escolas onde a escultura em questão foi exposta, o horizonte do universo das profissões ou ocupações é bastante reduzido, traduzindo em certa medida o universo de precariedade socio-economico daqueles alunos. Levar outras possibilidades tem nos parecido ser bem aceito.

Interessante observar, também, que os meninos se interessavam mais pelos materiais que eram resíduos eletrônico reaproveitados, pela tecnologia em si do que pela história dessa tecnologia.

\section{Considerações finais}

Para que intelectuais e cientistas como Ada Lovelace sejam reconhecidas e tenham seu trabalho valorizado é indispensável que se continue a planejar ações de incentivo, tanto nas escolas quanto nas universidades. Mulheres são pouco acolhidas nos meios de estudo em certas áreas de conhecimento, e mesmo as meninas jovens têm que lidar com hostilidade e controle dos seus corpos. A exclusão de mulheres dos espaços públicos e de intelectualidade tem diminuído, mas as marcas que a violência de gênero e a injustiça deixam numa sociedade devem demorar a deixar de ferir e restringir as pessoas desfavorecidas. Consideramos que com sensibilidade e constância podemos contribuir para a abertura de novos caminhos.

Seria pertinente avançar na proposta, levando os próprios alunos das escolas a construírem obras de arte representando mulheres da computação de sua escola, incentivando assim o protagonismo, não apenas a fruição propiciada pela exposição de obras.

\section{Referências}

Bim, Silvia Amelia. A vida de Ada Lovelace. SBC, 2018.

ESPELHO DIAMANTINO: Periodico de Politica, Litteratura, Bellas Artes, Theatro e Modas dedicado as Senhoras Brasileiras, O. $3^{\text {a }}$ ed. Rio de Janeiro, 1827. Disponível em: 〈https://goo.gl/Kf61hr>

Oliveira, Alyne C.; Moro Mirella M.; Prates, Raquel O. Perfil Feminino em Computação: Análise Inicial. In: Anais do XXXIV Congresso da SBC. XXII Workshop de Educação em Computação. 2014. p. 1465-1674.

SBC. Faltam mulheres na Ti. 2018. Disponível em 〈http://www.sbc.org.br/noticias/10-slideshow-noticias/2065-faltam-mulheres-na-ti >

SBC. Meninas digitais. 2019. Disponível em < http://meninas.sbc.org.br/>.

SCHWARTZ, Juliana; CASAGRANDE, Lindamir Salete; LESZCZYNSKI, Sonia Ana Charchut and CARVALHO, Marilia Gomes de. Mulheres na informática: quais foram as pioneiras?. Cad. Pagu [online]. 2006, n.27, pp.255-278. ISSN 0104-8333. http://dx.doi.org/10.1590/S0104-83332006000200010.

SCHIEBINGER, Londa. O feminismo mudou a ciência? Bauru-SP, EDUSC, 2001.

TROTMAN, Andrew. 2017. Why don't European girls like science or technology ? Disponível em < https://news.microsoft.com/europe/features/dont-european-girlslike-science-technology/>. Acesso em 12 mar 2019. 